\title{
Comparing psychological playfulness between the visually impaired and the sighted students in Iran
}

\author{
Mozhgan Jahanbakhsh ${ }^{1}$, Amir Ghamarani ${ }^{2, *}$ \\ ${ }^{1}$ Department of Psychology, Isfahan (Khorasgan) Branch, Islamic Azad University, Isfahan, Iran \\ ${ }^{2}$ Department of Special Education, University of Isfahan, Isfahan, Iran
}

Email address:

mozhganjahanbakhsh@gmail.com (M. Jahanbakhsh), a.ghamarani@edu.ui.ac.ir(A. Ghamarani)

To cite this article:

Mozhgan Jahanbakhsh, Amir Ghamarani. Comparing Psychological Playfulness between the Visually Impaired and the Sighted Students in Iran. American Journal of Applied Psychology. Vol. 3, No. 6, 2014, pp. 127-130. doi: 10.11648/j.ajap.20140306.12

\begin{abstract}
This research was aimed at comparing psychological playfulness between the visually impaired and their sighted counterparts. This study was performed using comparative-causative method,and the statistical population included all 14-18-year-old visually impaired and sighted male and female students in Isfahan, Iran. A total of 40 visually impaired and 40 sighted students were selected using random sampling method. The research instrument was the Short Measure of Adult Playfulness (SMAP; Proyer ,2012b).The research data was analyzed using SPSS in descriptive and inferential statistic levels. The descriptive statistics included indexes such as frequency, average, and Standard deviation, while the T test was applied in inferential statistics section. The obtained result indicated no significant difference in psychological playfulness between the visually impaired and the sighted students. This can be seen as first evidence of comparing psychological playfulness between the visually impaired and sighted student. Data are interpreted within current literature and future research directions are given.
\end{abstract}

Keywords: Psychological Playfulness, The Visually Impaired Student, Iran

\section{Introduction}

Both non-scientific and empirical studies show that special people are able to change almost every environment to make it more enjoyable and happy. These people are called "playful" (Barnett, 2007). Psychological playfulness is conceptualized as a personal state that becomes evident through the properties and characteristics people bring to their surrounding environment. Psychological playfulness is related to characteristics including being motivated towards achieving the goals, tendency towards participation in activities, tendency towards relating the object or behavior concepts to ourselves, and tendency towards neglecting the external regulations (Bozionelos and Bozionelos, 1996). To play and to be playful can facilitate enjoyment. Creating the repeated enjoyment of playing can always have wonderful effect in making a person in physical, intellectual, and social skills respects (Proyer, 2012). The playful people are often lively, full of energy, active, curious, creative, probing, spontaneous, humorous, unpredictable, adventurous, sociable, extrovert, and happy. They perform playful behavior through kidding, ridiculing, and sly behavior (Proyer and Ruch, 2011). Proyer (2011) define psychological playfulness as the tendency towards framing or reframing situation in such a way as to provide a person or perhaps others with entertainment, kidding and recreation. Barnett (1991) also defines psychological playfulness as the tendency towards participation and interaction in sly activities. Barnett (2007) suggested as a definition: "Playfulness is the predisposition to frame (or reframe) a situation in such a way as to provide oneself (and possibly others) with amusement, humor, and/or entertainment. Individuals who have such a heightened predisposition are typically funny, humorous, spontaneous, unpredictable, impulsive, active, energetic, adventurous, sociable, outgoing, cheerful, and happy, and are likely to manifest playful behavior by joking, teasing, clowning, and acting silly" (p. 955).

Peterson and Seligman (2004) also define psychological playfulness as an interest in laughing, kidding, and making others smile. They believe that the playful person has characteristics such as contest and appreciation, beauty, exaltation, leal, hope, and religiousness. According to Proyer and Ruch, some studies are conducted on positive psychology, which are not irrelevant to psychological playfulness, such as studies on positive excitement. According to Fredrickson (1998), to play and to be playful 
can increase the experience of joy and play, and enhance the physical, intellectual, and social skills gradually.Already Dewey (1913, cited, Prayer, 2012 ) described the intrinsic nature of play when he stated that play encompasses activities "which are not consciously performed for the sake of any result beyond themselves; activities which are enjoyable in their own execution without reverence to ulterior purpose" (p. 725). As playfulness is seen as intrinsically motivated. it was expected to demonstrate robust positive relations with intrinsic life goals. Furthermore, it was expected that greater playfulness relates to valuing the importance as well as the likelihood of intrinsic goals to occur. Extrinsic goals should be of lesser importance for playful adults. Nevertheless, it was expected that the higher perceived likelihood of extrinsic life goals should be related with playfulness. Furthermore, it was hypothetisized that exhibiting fun-variants of playful behavior may also be directed towards a specific aim; for example, for being perceived in a special way - e.g., as being eccentric, extravagant, interesting, or attractive. Thus, there may be an extrinsic gain in this kind of behavior. Exhibiting silly-variants of playfulness is expected to be unrelated from life-goals. This variant is most likely related to short-term intrinsic satisfaction but does not necessarily need to relate to any long-term aspirations. The intrinsic nature of playfulness should, as already mentioned, make flow-experiences more likely to occur and enable the experience of positive emotions(Prayer, 2012).

It also seems that the playful adults have an exciting and full of energy approach towards life. In a study by Proyer (2012), it was indicated that the more playful the people, the more their satisfaction and interest in a disorganized workplace and an abstract painting. No differences were observed in scoring an organized workplace and an organized painting portraying rectangular in different sizes. It can be said that the adult playful people work well in both workplaces. It is not indicated where working in each workplaces have beneficial and prohibiting effects on them. One hypothesis in this regard can be that the playful people have more opportunities for demonstrating their psychological playfulness in less organized and less arranged conditions. Perhaps they experience the drowning in a joyful activity more easily under these circumstances. Researchers have spent much effort in the study of play-especially of play in children (e.g., Barnett 1990; Schaefer et al. 1991).However; very little research is performed on teenage psychological playfulness, especially on the blind and visually impaired. Children with disabilities receive fewer positive responses to their social bids or attempts to engage in social interactions and, as a result, demonstrate less interest in their peers, which makes them more prone to social isolation(McConnell \& Odom, 1999).

The term "visual impairment" comprises a large span of situations ranging from mild vision problems to severe impairment; such as light perception only or completeloss of vision. Mild and severe visual impairment include a variety of vision problems such as myopia, far-sightedness, astigmatism, color blindness, night blindness, extreme sensitivity to light, dimness, haziness, foggy vision, spots in the visual field or reduced visual field(WHO,2010). According to the world health organization, 285 million people worldwide are visually impaired (WHO, 2012). Among them, 39 million (around 14\%) are blind. In geographical Europe the number of visually impaired people is estimated to over 30 million 2 and 6 million of them are blind. The number of people with a severe visual impairment is estimated to around 207000 . Most of the impairments could be cured or prevented. This is underlined by the fact that $90 \%$ of the people with visual impairment live in developing countries (WHO, 2012).

Visual impairment may result in a reduction of autonomy in daily life. Studies have indicated that children who are visually impaired demonstrate play behaviors that are predominantly exploratory in nature. These children engage less frequently in manipulative play, or the functional use of toys, and demonstrate more stereotypical behavior during play (Rettig, 1994). In addition, they infrequently engage in symbolic, highly imaginative, or role play and spend more time in solitary play or interacting with adults than with their sighted peers (Skellenger \& Hill, 1994). These limitations may be due to their inability to see how other children gain entry to play groups or sustain participation in group interactions. Hoben and Lindstrom (1980) found that visually impaired students initiated and responded less frequently to interactions that were initiated by their classmates than did their sighted peers. Sacks et al. (1992) observed that these children are less likely to respond to their peers' interests or to offer compliments to other children.

Whereas numerous studies have presented many arguments on the association of psychological playfulness with mental and physical health, psychological playfulness is not studied and analyzed in Iran, yet.

\subsection{Purpose of Research}

This research is aimed at comparing psychological playfulness between the visually impaired and the sighted students

\section{Method}

\subsection{Participants and Procedures}

This study was performed using comparative-causative method. The statistical population included all 14-18-year-old visually impaired and sighted male and female students in Isfahan, Iran. Therefore, a total of 40 sighted and 40 visually impaired students were selected using random sampling method.

\subsection{Research Instrument}

The Short Measure of Adult Playfulness (SMAP; Proyer ,2012b) is a five-item questionnaire for the assessment of playfulness in adults. It was developed for providing a global, cognitive self-description of playfulness. A sample item is "I am a playful person." All items are positively keyed and answers are given on a 4-point answer 
format (from 1 = "strongly disagree" to 4 = "strongly agree"). High scores in the SMAP indicate an easy onset and high intensity of playful experiences along with the frequent display of playful activities. Proyer reports best fit for a one-dimensional solution of the data (in exploratory and confirmatory factor analyses) and high internal consistencies ( $\geq .80$ in different samples). Furthermore, he found correlations in the expected direction and range with the need for play scale of the Personality Research Form (Jackson, 1984), Glynn and Webster's (1992), (1993) Adult Playfulness Scale, and a total score out of a list of adjectives set together based on Barnett's (2007) study, which was interpreted as support for its convergent validity. Support for the divergent validity of the instrument was found in negative relations with the seriousness scale out of the State-Trait-Cheerfulness Inventory (Ruch et al. 1996). Additionally, high and low scorers in the SMAP differed in the expected way in ratings for approval and disapproval of high and low complexity in workplaces and pieces of art. in this studty, the reliability of scale was calculated 0.80 through the Cronbach's Alpha

\subsection{Data Analysis}

Data was analyzed using SPSS in descriptive and inferential statistic levels. The descriptive statistics included indexes such as average, and Standard deviation, while the independent $\mathrm{T}$ test was applied in inferential statistics section.

\section{Result}

The data collected from the instruments will be entered into a computer file using SPSS. All inferential statistical analyses will use an alpha level of 0.05 . In this research, $T$ test was conducted to determine significant differences between visually impaired and the sighted students On psychological playfulness. Result indicate, no significant differences exist between groups at $\mathrm{p}<0.05$ level. That is the difference between the psychological playfulness in the sighted and the visually impaired students is not significant (Table 1).

Table 1. Comparing averages of psychological playfulness scores in the studied groups

\begin{tabular}{lrrrr}
\hline Group & Mean & $\begin{array}{l}\text { Std. } \\
\text { Deviation }\end{array}$ & T & P \\
\hline visually impaired & 16.85 & 3.93 & -1.90 & 0.06 \\
$\begin{array}{l}\text { students } \\
\text { sighted students }\end{array}$ & 18.42 & 3.43 & & \\
\hline
\end{tabular}

\section{Discussion}

This research was aimed at comparing psychological playfulness between the visually impaired and the sighted students. According to statistical analyses, it was indicated that there is no significant differences in psychological playfulness between the sighted and the visually impaired group. The psychological playfulness average and standard deviation were reported to be 85.16 and 93.3 respectively in the sighted, and 42.18 and 43.3 respectively in the visually impaired people. This finding is indirectly in line with findings by Nejati (2011), Ghamarani and Noori (2006, a,b), and Bozionelos and Bozionelos (1996).

Nejati (2011) studied and compared cognitive efficiency between the blind and sighted people. The result indicated that there is no significant difference in theirefficiency in cognitive functions such as activity initiation, flexibility, cautiousness, attention, emotions, and impulsive. Ghamarani and Noori (2006, a) compared and studied social skills among the blind students and their sited counterparts. Social skills include being impulsive, aggression, extreme self-confidence, contest, and relationship with peers. The results indicate no significant difference between them. Ghamarani and Noori $(2006, \mathrm{~b})$ studied self-image and its components among the blind students and their sited counterparts.It was indicated that the blind's abilities such as value, social, and sport is at a high level, and no differences exist between self-image and its general components in them. Bozionelos and Bozionelos (1996) analyzed the instrumental and expressive characteristics in association with psychological playfulness. They concluded that characteristics such as purposiveness, sensitivity, love, independence, activity, and willingness to respond is directly associated with psychological playfulness.

Elaborating on the results of these findings and their association with the present research, it can be said that characteristics such as activity, independence, love, sensitivity, purposiveness, willingness to respond, flexibility, impulsive, contest, and self-confidence are among the playful characteristics and this can express the lack of difference in psychological playfulness among these two groups. It can also be said that liveliness, spontaneity, hilarity and so on, are among the characteristics of psychological playfulness, and these characteristics are related to people's spiritual and mental conditions. The visual impairment cannot therefore create difference. Barnett (2007) also defined psychological playfulness as interaction and participation in sly activities. Considering that the participants here were those visually impaired students that could dominate their environment even with this amount of sight, and act somehow independently, the visual impairment cannot therefore be a differentiating factor in their psychological playfulness with that of the sighted people. The visually impaired are often aware of their environment because they see most of their surrounding things and phenomena. Therefore, it should not be imagined that the visually impaired live in an imaginary world. It should be considered that most activities and task does not require complete acuity. The visually impaired people can enhance their visually efficiency using the auxiliary tools and environmental adaption. The teenage and its characteristics can be considered as another elaboration. The participants were in the 14-18 years (teenage) group and an important feature for this Period is the tendency towards recreation and entertainment, happiness, liveliness, and an interest to play. Therefore, this factor can also elaborate on the lack of difference between these two groups. Regarding the findings of this research expressing no difference in psychological 
playfulness among the sighted and visually impaired people, it is suggested that studies be conducted on these two variables in fully blind people and in childhood and adolescence.

This research had a limitation, like other studies, that must be regarded when applying the findings. It was performed on the 14-18-year-old teenagers, and its results might not be generalizable to other age groups (i.e. the children or adults).

Additionally, it needs to be acknowledged the APS has been criticized in the literature as play in this conceptualization is seen as opposite of work on a single continuum and for psychometric shortcomings (see e.g., Barnett 2007; Krueger 1995). Therefore, follow-up studies should also consider alternative measures but also different data sources (e.g., behavior observations, diary methods, etc.).

\section{References}

[1] Barnett, LA (1990). Playfulness: Definition, design, and measurement. Play and Culture, 3: 319-336.

[2] Barnett, LA (1991). The playful child: Measurement of a disposition to play. Play and Culture, 4: 51-74.

[3] Barnett, L. A. (2007). The nature of playfulness in young adults. Journal of Personality and Individual Differences, 43: 949-958.

[4] Bozionelos, N, Bozionelos G. (1996). Playfulness: its relationship with instrumental and expressive traits. Journal of Personality and Individual Differences, 26:749-760.

[5] Fredrickson, B.L .(1998). What good are positive emotions? Review of General Psychology, 2(3): 300-319.

[6] Ghamarani, A., \& Noori, S. (2006, a) Compared social skills among the blind students and their sited counterparts. Journal of Special Education, 45, 2-7. (Persian).

[7] Ghamarani, A., \& Noori, S. (2006, b) Compared self-image and its components among the blind students and their sited counterparts. Journal of Special Education, 49, 6-14.(Persian).

[8] Glynn, MA, \& Webster, J. (1992). The Adult Playfulness Scale: An initial assessment. Psychological Reports, 71, 83-103.

[9] Glynn, MA, \& Webster, J (1993). Refining the nomological net of the Adult Playfulness Scale: Personality, motivational, and attitudinal correlates for highly intelligent adults. Psychological Reports, 72, 1023-1026.

[10] Hoben, M., \& Linstrom, V. (1980). Evidence of isolation in the mainstream. Journal of Visual Impairment \& Blindness, 74, 289-292.

[11] Jackson, DN (1984). Personality Research Form manual. 23, 26-50. Port Huron, MI: Research Psychologists Press.
[12] Krueger, A (1995). The Adult Playfulness Scale: A review. Psychology, 32, 36-38.

[13] McConnell, S., \& Odom, S. (1999). A multimeasure performance-based assessment of social competence in young children with disabilities. Topics in Early Childhood Special Education, 19(2), 67-74.

[14] Nejati, V.(2011). Compare cognitive efficiency between the blind and sighted people.Ofoghe Danesh, Journal of Gonabad University of Medical Sciences and Healh,2,16-25. (Persian).

[15] Proyer, R.T. (2011) .Being playful and smart? The relations of adult playfulness with psychometric and self-estimated intelligence and academic performance. Journal of Learning and Individual Differences, 21:463-467.

[16] Proyer, R.T. (2012b). Development and initial assessment of a short measure for adult playfulness: The SMAP. Journal of Personality and Individual Differences, 15: 512-527.

[17] Proyer, RT. (2012). A psycho-linguistic study on adult playfulness:Its hierarchical structure and theoretical considerations. Journal of Adult Develop, 19:141-149.

[18] Proyer, R.T., Ruch, W. (2011). The virtuousness of adult playfulness: the relation of playfulness with strengths of character. Department of Psychology, Division on Personality and Assessment, 5: 522-2211.

[19] Peterson, C., Seligman, M.E. P. (2004). Character strengths and virtues: A handbook and classification. Washington, DC: American Psychological Association.

[20] Rettig, M. (1994). The play of young children with visual impairments: Characteristics and interventions. Journal of Visual Impairment \& Blindness, 88, 10-420.

[21] Ruch, W., Köhler, G. \& van Thriel, C. (1996). 'Assessing the "humorous temperament": Construction of the facet and standard trait forms of the State-Trait-Cheerfulness-Inventory - STCI'. Humor: International Journal of Humor Research, 9, pp.303-339.

[22] Sacks, S. K., Kekelis, L. S., \& Gaylord-Ross, R. J. (Eds.). (1992). The development of social skills by blind and visually impaired students: Exploratory studies and strategies. New York: American Foundation for the Blind.

[23] Schaefer, C.E. , Gitlin, K.,\& Sandgrund, A. (1991). Play diagnosis and assessment. New York: Wiley.

[24] Skellenger, A., \& Hill, E. (1994). Effects of a shared teacher-child play intervention on the play skills of three young children who are blind. Journal of Visual Impairment \& Blindness, 88, 433-445.

[25] WHO. (2010). International Classification of Diseases (ICD-10). Geneva, Switzerland: World Health Organization.

[26] WHO. (2012). Visual Impairment and blindness Fact Sheet $\mathrm{N}^{\circ}$ 282. World Health Organization. 